\title{
Identification of matrix metalloproteinase-9 as an independent prognostic marker in laryngeal and hypopharyngeal cancer with opposite correlations to adhesion/growth-regulatory galectins- 1 and -7
}

\author{
SVEN SAUSSEZ ${ }^{1,2}$, STÈPHANIE CLUDTS ${ }^{1}$, AURELIE CAPOUILLEZ ${ }^{1}$, GEOFFREY MORTUAIRE ${ }^{3}$, \\ KAREL SMETANA $\mathrm{Jr}^{5}$, HERBERT KALTNER ${ }^{6}$, SABINE ANDRÉ ${ }^{6}$, XAVIER LEROY ${ }^{4}$, \\ HANS-JOACHIM GABIUS $^{6}$ and CHRISTINE DECAESTECKER ${ }^{7}$
}

\begin{abstract}
${ }^{1}$ Laboratory of Anatomy, Faculty of Medicine and Pharmacy, University of Mons-Hainaut, Mons, Belgium;
${ }^{2}$ Department of Oto-Rhino-Laryngology, Faculty of Medicine, CHU Saint-Pierre, Brussels, Belgium; Departments of ${ }^{3}$ Oto-Rhino-Laryngology and ${ }^{4}$ Pathology, Faculty of Medicine, Hôpital Claude Huriez and Centre de Biologie-Pathologie-CHRU, Lille, France; ${ }^{5}$ Institute of Anatomy, First Faculty of Medicine, Charles University, Prague, Czech Republic; ${ }^{6}$ Institute of Physiological Chemistry, Faculty of Veterinary Medicine, Ludwig-Maximilians-University, Munich, Germany; ${ }^{7}$ Laboratory of Toxicology, Institute of Pharmacy, Université Libre de Bruxelles, Brussels, Belgium
\end{abstract}

Received August 19, 2008; Accepted October 6, 2008

DOI: 10.3892/ijo_00000167

\begin{abstract}
The enzymatic activity of matrix metalloproteinase-9 (MMP-9) suggests that its presence in hypopharyngeal and laryngeal squamous cell carcinomas (HSCCs, LSCCs) could have prognostic value. We tested this hypothesis by quantitative morphometric analysis of immunohistochemical staining in histological sections of 73 stage IV HSCCs and 45 LSCCs (30 cases of stage I/II, 15 cases of stage IV). As compared to tumour-free epithelium an increase for the labelling index in LSCCs reached statistical significance $(p=0.04)$. Specimens of Reinke's edema were strongly higher in this parameter compared to tumour-free tissue area $(\mathrm{p}=0.000001)$, underscoring an association between the level of MMP-9 expression and inflammation. Focusing on patients' recurrence status we identified thresholds for the labelling index of $10 \%$ for HSCCs and $18 \%$ for LSCCs, both indicating rapid recurrence and dismal prognosis unless surpassed. When relating data for MMP-9 to those for three adhesion/growth-regulatory galectins, a positive correlation with galectin-7 expression was detected in LSCCs. This finding suggests a possible potential role of this endogenous lectin as inducer of MMP-9 gene expression in situ. Of note, galectin-1 expression was negatively correlated with MMP-9
\end{abstract}

Correspondence to: Professor S. Saussez, Laboratory of Anatomy, Faculty of Medicine and Pharmacy, University of MonsHainaut, Pentagone 1B - Avenue du Champ de Mars 6, B-7000 Mons, Belgium

E-mail: sven.saussez@umh.ac.be

Key words: collagenase IV, extracellular matrix, gelatinase, lectin, prognosis, relapse-free survival and that of galectin-3, a substrate of MMP-9, not related. In conclusion our study delineated a prognostic role of MMP-9 immunodetection in high-stage HSCCs and in LSCCs when separating patients by a distinct threshold for the labelling index. Moreover, it indicated associations between MMP-9 and multifunctional galectins- 1 and -7 in situ .

\section{Introduction}

Promotion of invasion of tumour cells into parenchymal tissue and of angiogenesis are hallmarks of consequences of the activity of matrix metalloproteinases (MMPs) (1-3). To gauge their potential as predictors for a certain clinical course systematic monitoring of their expression is a reasonable step. Focusing on MMP-9 (92 kDa gelatinase B, type IV collagenase) and head and neck cancer, the current status of respective research intimates its potential to serve as prognostic marker, although clear-cut relations were not apparent in each study setting (4-12). Moreover, this enzyme's expression in squamous cell carcinoma of skin and oesophagus was associated with elevated degree of inflammation when stromal or with depth of invasion, respectively (13-15). To clarify the value of MMP-9 immunodetection for prognostic assessments a salient factor is the analysis of a sufficiently large cohort of clinical specimens. Our series of material from 73 patients of stage IV hypopharyngeal squamous cell carcinoma (HSCC) clearly met this requirement. We added to this study part a total of 45 specimens of laryngeal squamous cell carcinoma (LSCC) from 30 stage I/II and 15 stage IV patients. This panel enabled setting the MMP-9 staining profiles of H/LSCCs in relation to clinical parameters, with all specimens thus deliberately processed under identical conditions. Experimentally, all immunohistochemical staining patterns were subjected to quantitative morphometry. We 
recorded the signal intensity and the immunostained area in each case. These data were then analyzed following a discrimination-based approach with the aim to identify threshold values with optimal capacity to separate groups of patients with prognostic relevance retrospectively (16). Thus, we applied quantitative immunohistochemistry together with systematic group building to pinpoint, if possible, discriminatory parameters.

Of note, these panels of specimens have previously been studied with respect to an emerging class of adhesion/ growth-regulatory effectors, i.e. galectins (17-19). Further insights into the signature of marker presence will thus be gained for the same cases. In detail, galectins- 1 and -7 had been characterized as predictors of recurrence in LSCCs and HSCCs, respectively, whereas galectin-3 was found to be upregulated without predictive potential (20-23). What's more and intriguing, there are even indications for a direct connection between galectins and MMP-9: galectin-3 is a substrate of this enzyme, which removes the lectin's collagenous-like section and hereby impairs its tendency for pentamerization without harming its lectin activity (24), and galectin-7, also known as p53-induced gene 1, induces MMP-9 gene expression in the human diffuse large B cell line Ocy-2 by virtue of binding cell surface glycans (25). Availability of these data sets afforded the opportunity to figure out any statistical associations between the expression levels of MMP-9 and these galectins in clinical material. In sum, our report will answer the following questions: i) will the level of MMP-9-dependent staining be elevated in HSCCs and/or LSCCs? ii) will there be statistical significance for a disease-associated change? iii) will processing of the quantitative data using a discrimination-based approach spot thresholds separating groups of patients with prognostic relevance? and iv) will there be correlations between the staining profiles of MMP-9 and galectins-1,-3 and -7?

\section{Materials and methods}

Patient characteristics. Material from a total of 118 cases was studied (73 patients with stage IV HSCC and 45 patients with LSCC distributed over stages I, II and IV who underwent surgery aimed at curative tumour resection; see Table I for clinical data). The individual cases were compiled by retrospective review from the records of the ENT Department of the Hôpital Claude Huriez (Lille, France), covering the period from January 1989 to December 2001. The description of the tumour status was based on the histological stage of tumour differentiation, criteria defined in (26), and the TNM classification (27). Detailed information in all cases was available on extent of surgical resection, response to treatment at the primary tumour site and follow-up data up to the last contact with the patient, when the status of the disease was assessed. Patients suffering from SCCs localised at other sites of the head and neck area were deliberately excluded from this study. To compare MMP-9 expression features measured in carcinoma tissue with that in tumour-free tissue areas and benign lesions, we additionally analyzed 10 cases of tumour-free epithelium in the vicinity of the laryngeal and hypopharyngeal carcinomas and 25 benign lesions of vocal folds (i.e. Reinke's edema).
Table I. Clinical data.

\begin{tabular}{lccc}
\hline Variable & $\begin{array}{c}\text { High- } \\
\text { stage } \\
\text { HSCCs }\end{array}$ & $\begin{array}{c}\text { Low- } \\
\text { stage }\end{array}$ & $\begin{array}{c}\text { High- } \\
\text { stage }\end{array}$ \\
& & & \\
& & & \\
\hline Age (years) & & & \\
Range & $40-78$ & $36-88$ & $43-78$ \\
Average & 55 & 57 & 57 \\
Sex (cases) & & & \\
Male & 73 & 30 & 15
\end{tabular}

Female

Site (cases)

Supraglottic area 3

Glottic area

Supraglottic and glottic areas

Subglottic and glottic areas

Piriform sinus

60

Postcricoid area

12

Posterior wall

1

Histological grade (cases)

Well differentiated 38

$27 \quad 10$

Moderately differentiated

Poorly differentiated

Stage (cases)

I

II

IV

Tumour treatment (cases)

$\mathrm{Co}_{2}$ laser cordectomy

Frontolateral laryngectomy

Vertical partial laryngectomy

Supracricoid partial laryngectomy

Supraglottic laryngectomy

Total laryngectomy

Partial pharyngolaryngectomy 9

Total pharyngolaryngectomy $\quad 50$

Circular pharyngolaryngectomy 6

Esopharyngolaryngectomy $\quad 8$

Treatment of the neck (cases)

Functional neck dissection

19

23

Radical neck dissection

2

Recurrence (cases)

Local recurrence

Distant recurrence

14

8

4

Follow-up

Range (months)

2-122 2-130 5-74

Average (months)

$\begin{array}{lll}37 & 43 \quad 30\end{array}$


Western blot. Protein extracts from cell pellets of the murine SCC-VII squamous cell carcinoma line and human laryngeal, hypopharyngeal and oropharyngeal squamous cell carcinomas (10 cases) were processed using standard electroblotting and chemiluminescence protocols for MMP-9 immunodetection with the commercial primary antibody (please see below) as previously described (23).

Immunohistochemistry. Specimens were routinely fixed for $24 \mathrm{~h}$ in $4 \%$ formaldehyde, dehydrated and embedded in paraffin. The immunohistochemical processing with inherent specificity controls had previously been standardised to allow direct comparisons, starting from $5 \mu$ m-thick sections mounted on silane-coated glass slides (20-23). Briefly, dewaxed tissue sections were first subjected to a microwave step in $0.01 \mathrm{M}$ citrate buffer ( $\mathrm{pH} \mathrm{6.0)}$ ) for $2 \times 5 \mathrm{~min}$ at $900 \mathrm{~W}$. The sections were then incubated with a solution of $0.4 \%$ hydrogen peroxide for 5 min to block endogenous peroxidase activity, carefully rinsed in phosphate-buffered saline (PBS; $0.04 \mathrm{M}$ $\mathrm{Na}_{2} \mathrm{HPO}_{4}$ and $0.01 \mathrm{M} \mathrm{KH}_{2} \mathrm{PO}_{4}$ containing $0.12 \mathrm{M} \mathrm{NaCl}$, $\mathrm{pH}$ 7.4) and successively exposed for a period of $20 \mathrm{~min}$ each to solutions containing avidin $(0.1 \mathrm{mg} / \mathrm{ml}$ in PBS $)$ and biotin $(0.1 \mathrm{mg} / \mathrm{ml}$ in PBS $)$ to saturate endogenous biotin in order to avoid false-positive staining reactions. After thorough rinsing with PBS to remove reagents, the sections were incubated for 20 min with a solution of $0.5 \%$ casein in PBS to ensure saturation of sites with binding capacity to (glyco)proteins and then sequentially exposed at room temperature i) to the specific primary antibody (please see below); ii) to the corresponding biotinylated secondary antibody (polyclonal goat anti-rabbit IgG antibody); and iii) to the avidin-biotin-peroxidase complex (ABC kit). The antigen-dependent presence of labelled peroxidase in the sections was visualized by incubation with the chromogenic substrate mix containing diaminobenzidine and $\mathrm{H}_{2} \mathrm{O}_{2}$. After careful rinsing, the sections were counterstained with luxol fast blue and mounted with a synthetic medium. For control to rigorously exclude antigen-independent staining (e.g. by binding of the high-mannose-type glycan chains of the glycoprotein horseradish peroxidase to mannose-specific lectins in the sections) the incubation step with the primary antibody was either omitted or replaced by incubation with non-immune antiserum. In all tested cases these controls were negative (data not shown). The biotinylated secondary antibody and the ABC kit came from DakoCytomation (Glostrup, Denmark), and the rabbit polyclonal anti-MMP-9 antibody from Chemicon (Temecula, CA, USA). The data on galectin expression profiles, using non-cross-reactive antibodies against the human proteins after purification and quality controls under identical conditions, have previously been published (20-23).

Computer-assisted microscopy. Having completed staining, its distribution and intensity were quantitatively determined by a computer-assisted KS 400 imaging system (Carl Zeiss Vision, Hallbergmoos, Germany), as detailed previously (20). For each case we scanned 15 fields corresponding to surface areas ranging from 60,000 to $120,000 \mu \mathrm{m}^{2}$. This morphometric analysis computed the following two parameters: i) the labelling index (LI), i.e. the percentage of positive

\section{scC-VII cell line}

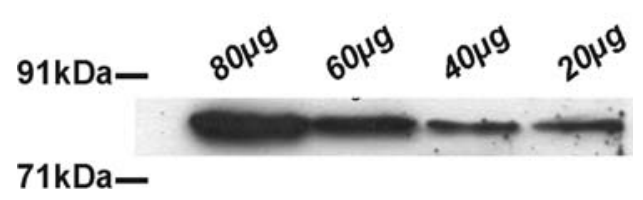

Figure 1. Western blot of an extract from the murine SCC-VII squamous cell carcinoma line revealing the typical band for an active form of MMP-9 at $86 \mathrm{kDa}$ and the concentration dependence.

tissue area after processing with the given marker; and ii) the mean optical density (MOD), i.e. the mean staining intensity of the positive area.

Data analysis. The numerical values obtained for independent groups were compared using the non-parametric Mann-Whitney U (two groups) or Kruskall-Wallis tests (more than two groups). In the case of significant KruskallWallis tests, group pairs were compared by means of the appropriate post-hoc (Dunn) procedure in order to avoid multiple comparison effects. Standard survival-time analyses followed the Kaplan-Meier procedure and the Gehan's generalized Wilcoxon test. As previously described (21), the quest for threshold values enabling to separate groups of patients with very different clinical courses such as patients with/without recurrence after a period of 24 months postsurgery was based on a discrimination-based technique using the Gini Index (such as in the decision tree approach). This method aims to systematically test different threshold values applied on a certain parameter in order to identify the one with the best discriminatory power between the two groups of patients of interest $(20,21)$. Correlation between numerical variables was analyzed by means of the nonparametric Spearman correlation test. All the statistical analyses were performed with the Statistica software (Statsoft, Tulsa, AZ, USA).

\section{Results}

Detection of MMP-9 by Western blotting. Prior to starting immunohistochemical processing we challenged the quality of the antibody by a control in Western blots to verify its specificity, the absence of cross-reactivity and, crucial for quantitative morphometry, the concentration dependence in antigen detection. Using increasing protein quantities of extracts from the murine SCC-VII squamous cell carcinoma cell line, a characteristic band of $86 \mathrm{kDa}$ for an active MMP-9 form was detected, no evidence for cross-reactivity seen and increasing signal intensity measured in titrations (Fig. 1). Additionally, we processed extracts from 5 laryngeal and hypopharyngeal squamous cell carcinomas, invariably visualizing an active form of MMP-9 at Mr $67 \mathrm{kDa}$ (data not shown). These results established a firm basis to proceed to immunohistochemical monitoring, starting with the comparison of staining profiles of tumour-free controls, benign lesions and carcinomas.

Quantitative morphometry of MMP-9-dependent staining. The morphological examination of the hypopharyngeal tissue 

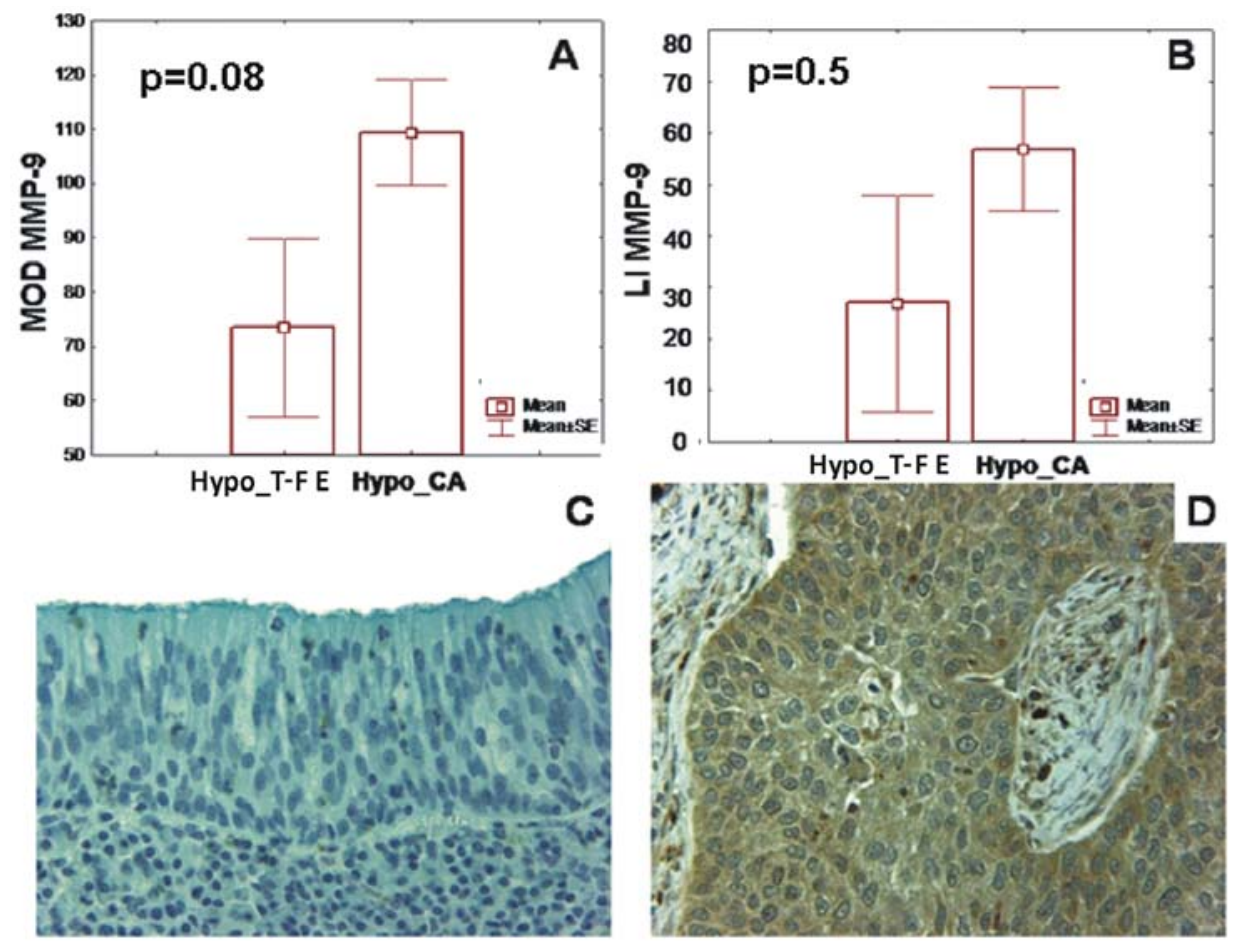

Figure 2. Quantitative determination (by computer-assisted microscopy) of the intensity of MMP-9-dependent immunohistochemical staining (MOD: mean optical density) (A) and the percentage of MMP-9-immunopositive tissue area (LI: labelling index) (B) in a series of 10 cases of tumour-free epithelium (T-F E) compared with 73 specimens of hypopharyngeal stage IV carcinoma (Hypo_CA) (A and B). Examples of staining profiles for a case of tumour-free hypopharyngeal epithelium (T-F E) (C) and of hypopharyngeal carcinoma (D), respectively. (C and D) Magnification x320.
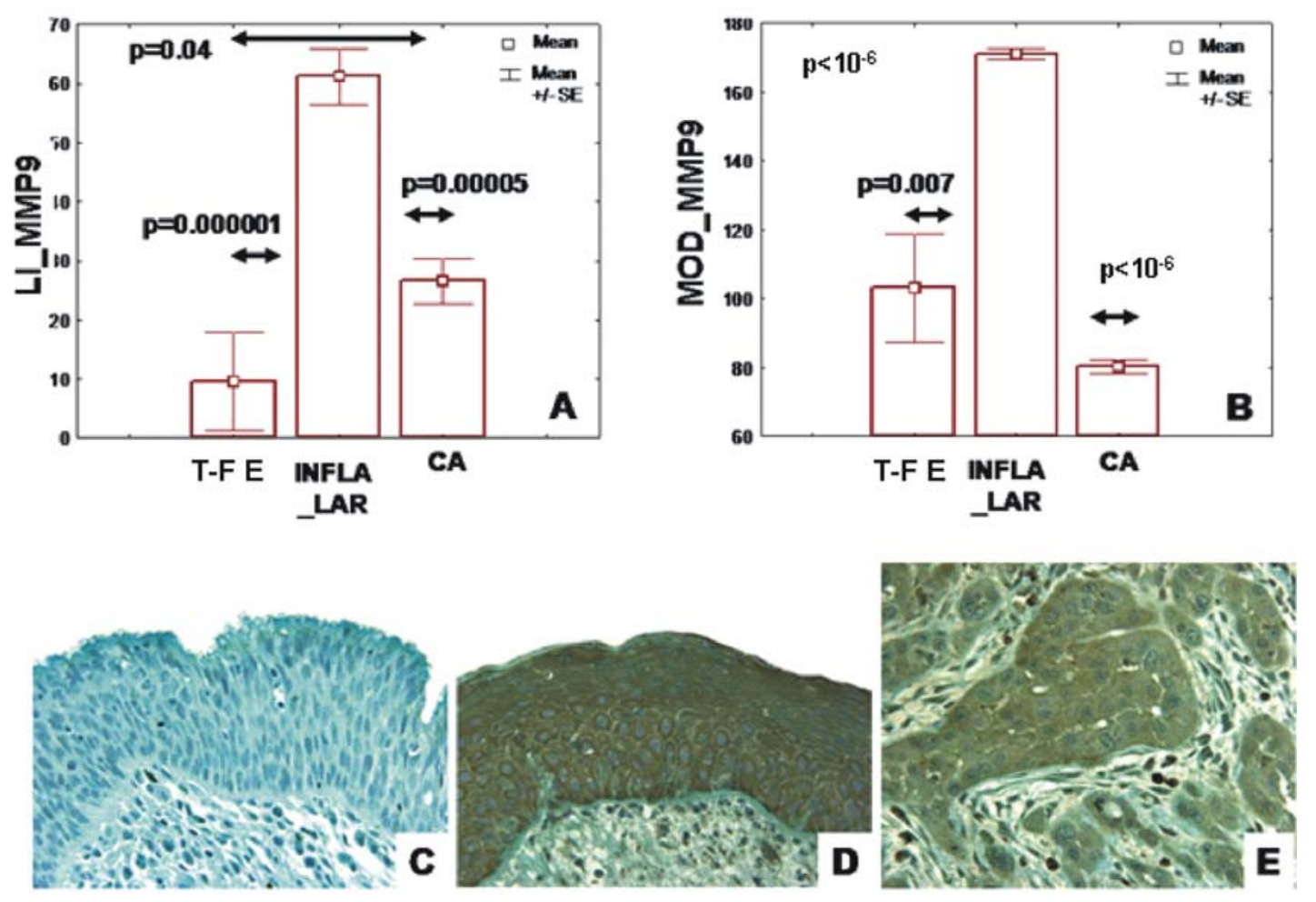

Figure 3. Quantitative determination (by computer-assisted microscopy) of the intensity of MMP-9-dependent immunohistochemical staining (MOD) (B) and the percentage of MMP-9-immunopositive tissue area (LI) (A) in a series of 10 cases of tumour-free epithelium (T-F E), 25 cases of benign lesions of vocal folds (Infla_Lar) and 45 cases of laryngeal carcinomas (CA) (A and B). Examples of staining profiles for a case from each group, i.e. tumour-free laryngeal epithelium (T-F E) (C), benign lesion of the vocal fold (D) and laryngeal carcinoma (E). (C-E) Magnification x320.

specimens consisting of 10 cases of peritumoural epithelia with no sign of malignancy (T-F E) and 73 cases of stage IV carcinomas (CA) provided no clear evidence for significant differences (Fig. 2). In histological detail, tumour-free hypo- 
HYPHOPHARYNX
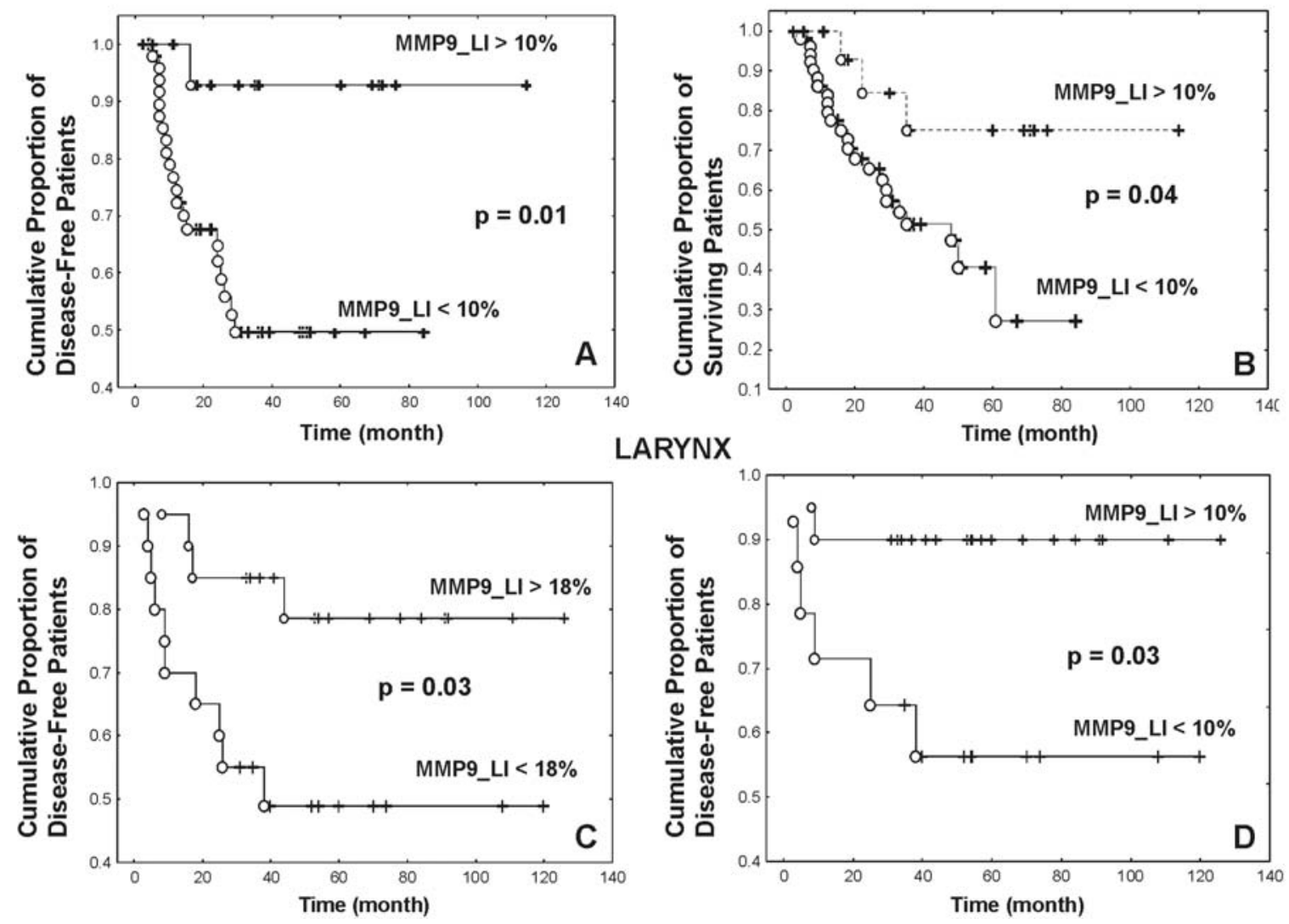

Figure 4. Remission and survival curves in hypopharyngeal (A and B) and laryngeal (C and D) tumours for the two groups of patients identified on the basis of the LI parameter and the thresholds given in each panel (A and C). Patients with/without tumour recurrences are defined by black dots/crosses; deceased/living patients are indicated by dots/crosses (B and D). The p-values were computed using the Gehan's generalized Wilcoxon test.

pharyngeal epithelium presented a weak MMP-9-dependent immunostaining in both nuclear and cytoplasmic compartments in all layers. In contrast, sections of hypopharyngeal carcinomas documented MMP-9 presence mostly located in the cytoplasm.

Studying laryngeal specimens (i.e. 10 cases of peritumoural epithelia with no sign of malignancy, 25 cases of Reinke's edema (inflammatory larynx, Infl_Lar) and 45 carcinomas) in the same manner came up with a significant increase in the labelling index (post-hoc test; $\mathrm{p}=0.04$ ) (Fig. 3). A dramatic enhancement relative to the controls was seen in inflammation (post-hoc test; $\mathrm{p}=0.000001$ ) (Fig. 3). With respect to location, the immunolabelling was mostly cytoplasmic and concerned all layers of the epithelium in tumourfree epithelium and in specimens of Reinke's edema, whereas additional nuclear positivity was frequent in the carcinoma specimens (Fig. 3). Having herewith defined MMP-9 presence in quantitative terms and on the cellular level, the relations to clinical parameters were addressed next.

Prognostic relevance of MMP-9-dependent parameters. Based on systematic data processing optimal thresholds could be defined to separate patient groups according to any of the two quantitative parameters. In each tumour group, the labelling index proved valid for classifying patients into two groups presenting significant differences with respect to tumour recurrence (Fig. 4A, C and D) and survival (Fig. 4B). Explicitly, patients suffering from a stage IV hypopharyngeal carcinoma with a MMP-9 labelling index below 10\% were more likely prone to recurrences and dismal prognoses. Of note, when confronted with clinical features this parameter was evidenced as an independent prognostic marker in this group of stage IV tumours (data not shown). This conclusion was similarly reached for the group of patients with laryngeal carcinomas. Low extents of labelling index were associated with adverse clinical course of the disease. Having indicated evidence for mutual regulation of MMP-9/galectin activities in the introduction, the presented data were instrumental in initiating answers to the question on correlations between the quantitative parameters of both classes of marker in situ.

Are there correlations of staining parameters between MMP-9 and galectins $-1,-3$ and -7 ? The respective data analysis for the hypopharyngeal carcinomas did not evidence any significant correlation. However, the analysis of the data sets for the laryngeal tumours identified significant correlations, even with opposing directions for the two homodimeric galectins-1 and -7 (Fig. 5). These latter results exclusively concerned the labelling index. In detail, a positive correlation associates high percentages of positive tumour area for MMP-9 and galectin-7 together, whereas this relation is reversed in the case of galectin-1. 


\section{Laryngeal carcinomas}

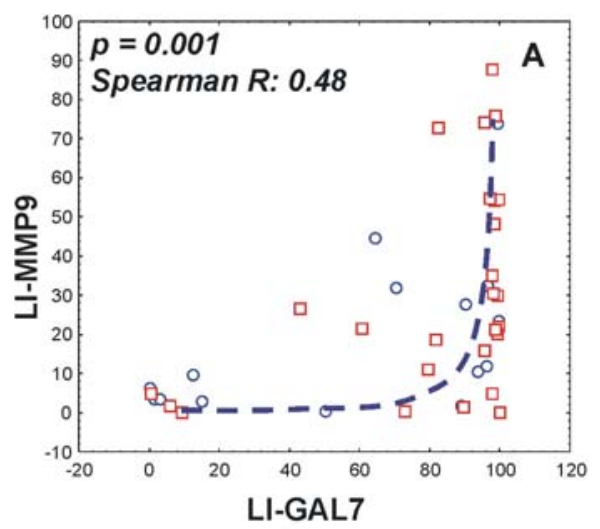

OHigh stage

口Low stage

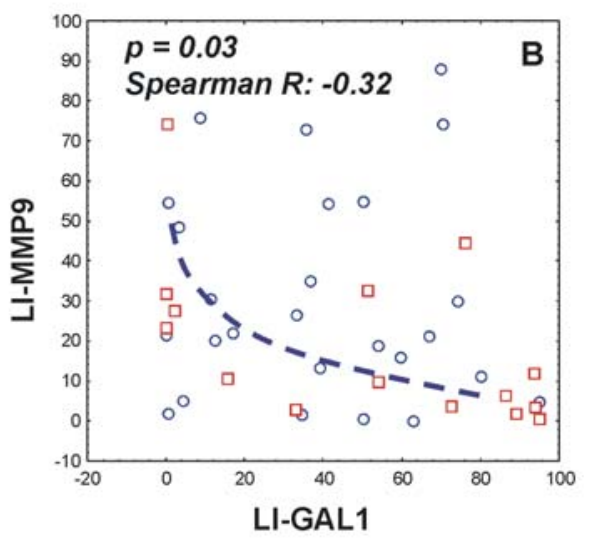

O High stage

$\square$ Low stage

Figure 5. Correlations of LI data between MMP-9 and either galectin-7 (A) or galectin-1 (B) in LSCC cases, identifying low- and high-stage tumour cases.

\section{Discussion}

This study contributed to clarify the status of immunohistochemical monitoring of MMP-9 in stage IV HSCCs and in LSCCs. A significant increase was only observed for the labelling index in LSCCs as compared to control. It should yet be noted that this control was peritumoural tissue with normal appearance. As observed in basal cell carcinoma of the skin (28), it cannot definitively be excluded that peritumoural regions harbor above-baseline levels of MMP-9 expression. Of further note, the specimens from patients with Reinke's edema by far surpassed this level, connecting MMP-9 to inflammation.

Moving on with processing the quantitative data for prognostic purpose, efficient thresholds were found for assigning patients (with each tumour type) to two groups signifying relapse-free and overall survival. If the labelling index remained below $10 \%$, then relapse-free survival was shortened with a dismal prognosis. Although this result may appear as counter-intuitive, beneficial effects of MMP-9 should not be overlooked, which e.g. led to restrict aggressiveness of tumours seen in a model of skin cancer $(29,30)$. Also sections of node-negative breast cancer cases had revealed MMP-9 positivity as independent favourable predictor of overall survival ( $\mathrm{p}=0.03$ ) (31). In clinical terms, our data intimate that the possibility arises to subdivide patients of stage IV HSCCs and of LSCCs using the given threshold for different treatment options.

The comparison between the data sets for MMP-9 presented herein and for galectins-1,-3 and -7 (20-23) indicated two divergent correlations in the case of LSCCs. The positive correlation with galectin-7 is in line with its potential in vitro to promote MMP-9 gene expression in a lymphoma model (25), whereas a negative association with no in vitro precedent was disclosed for galectin-1 (32). Divergence in ligand recognition and disparate signaling pathways are indeed known even for these two members of the homodimeric subgroup of galectins $(19,33)$. Already a slight shift in cell surface glycosylation, e.g. in core substitutions or sialylation $(34,35)$, can be translated into distinct effects by different interpretors of the sugar code in the galectin network (36). Since our work identified uncovered remarkable associations between MMP9 presence and the clinical course as well as galectins- 1 and -7 , it is now tempting to move on along this line. In fact, another member of the galectin family, i.e. the tandem-repeat-type galectin-8, appears to be directly involved in the processing of the MMP-9 precursor proMMP-9 by MMP-3. Whereas galectins- 1 and -3 had no influence on MMP-9 production by MMP-3 in neutrophils, galectin- 8 accelerated this process conspicuously (37). This observation together with the presented clinical evidence for a correlation between MMP-9 and galectins-1 and -7 give a clear direction for future research toward extending the insights into the galectin network and its relationship to MMP-9 in head and neck cancer.

\section{Acknowledgements}

We gratefully acknowledge the generous financial support by the Fondation Vésale, the research initiative LMUexcellent, the Verein zur Förderung des biologisch-technologischen Fortschritts in der Medizin e.V. (Heidelberg, Germany) and an EC Marie Curie Research Training Network (contract no. MCRTN-CT-2005-19561). C.D. is a Senior Research Associate with the Belgian National Fund for Scientific Research (FNRS, Brussels, Belgium).

\section{References}

1. Sternlicht MD and Werb Z: How matrix metalloproteinases regulate cell behavior. Annu Rev Cell Dev Biol 17: 463-516, 2001.

2. Folgueras AR, Pendás AM, Sánchez LM and López-Otín C: Matrix metalloproteinases in cancer: from new functions to improved inhibition strategies. Int J Dev Biol 48: 411-424, 2004.

3. Noël A, Jost M and Maquoi E: Matrix metalloproteinases at cancer tumor-host interface. Semin Cell Dev Biol 19: 52-60, 2008. 
4. Miyajima Y, Nakano R and Morimatsu M: Analysis of expression of matrix metalloproteinases-2 and -9 in hypopharyngeal squamous cell carcinoma by in situ hybridization. Ann Otol Rhinol Laryngol 104: 678-684, 1995.

5. Charous SJ, Stricklin GP, Nanney LB, Netterville JL and Burkey BB: Expression of matrix metalloproteinases in head and neck squamous cell carcinoma. Ann Otol Rhinol Laryngol 106: 271-278, 1997

6. Riedel F, Götte K, Schwalb J, Bergler W and Hörmann K: Expression of 92-kDa type IV collagenase correlates with angiogenic markers and poor survival in head and neck squamous cell carcinoma. Int J Oncol 17: 1099-1105, 2000

7. Franchi A, Santucci M, Masini E, Sardi I, Paglierani M and Gallo O: Expression of matrix metalloproteinase-1, matrix metalloproteinase-2 and matrix metalloproteinase-9 in carcinoma of the head and neck. Cancer 95: 1902-1910, 2002.

8. Christopoulos TA, Papageorgakopoulou N, Theocharis DA, Aletras AJ, Tsiganos CP, Papadas TA, Mastronikolis NS, Goumas P and Vynios DH: Diagnostic and classification value of metalloproteinases in squamous human laryngeal carcinoma. Int J Oncol 25: 481-485, 2004.

9. Ruokolainen H, Pääkkö P and Turpeenniemi-Hujanen T: Expression of matrix metalloproteinase-9 in head and neck squamous cell carcinoma: a potential marker for prognosis. Clin Cancer Res 10: 3110-3116, 2004.

10. Ruokolainen H, Pääkkö P and Turpeenniemi-Hujanen T: Serum matrix metalloproteinase-9 in head and neck squamous cell carcinoma is a prognostic marker. Int J Cancer 116: 422-427, 2005.

11. Christopoulos TA, Papageorgakopoulou N, Ravazoula P, Mastronikolis NS, Papadas TA, Theocharis DA and Vynios DH: Expression of metalloproteinases and their tissue inhibitors in squamous cell laryngeal carcinoma. Oncol Rep 18: 855-860, 2007.

12. Patel BP, Shah SV, Shukla SN, Shah PM and Patel PS: Clinical significance of MMP-2 and MMP-9 in patients with oral cancer. Head Neck 29: 564-572, 2007.

13. Dumas V, Kanitakis J, Charvat S, Euvrard S, Faure M and Claudy A: Expression of basement membrane antigens and matrix metalloproteinases-2 and -9 in cutaneous basal and squamous cell carcinomas. Anticancer Res 19: 2929-2938, 1999.

14. Tanioka Y, Yoshida T, Yagawa T, Saiki Y, Takeo S, Harada T, Okazawa T, Yanai $\mathrm{H}$ and Okita K: Matrix metalloproteinase-7 and matrix metalloproteinase- 9 are associated with unfavourable prognosis in superficial oesophageal cancer. Br J Cancer 89: 2116-2121, 2003

15. O'Grady A, Dunne C, O'Kelly P, Murphy GM, Leader M and Kay E: Differential expression of matrix metalloproteinase (MMP)-2, MMP-9 and tissue inhibitor of metalloproteinase (TIMP)-1 and TIMP-2 in non-melanoma skin cancer: implications for tumour progression. Histopathology 51: 793804, 2007.

16. Decaestecker C, Camby I, Remmelink M, Nagy N, Petein M, Pasteels JL, Van Ham P, Salmon I and Kiss R: Decision tree induction: a useful tool for assisted diagnosis and prognosis in tumor pathology. Lab Invest 76: 799-808, 1997.

17. Gabius HJ, Siebert HC, André S, Jiménez-Barbero J and Rüdiger H: Chemical biology of the sugar code. Chembiochem 5: 740-764, 2004.

18. Smetana K Jr, Dvoránková B, Chovanec M, Boucek J, Klíma J, Motlík J, Lensch M, Kaltner H, André S and Gabius HJ: Nuclear presence of adhesion/growth-regulatory galectins in normal/ malignant cells of squamous epithelial origin. Histochem Cell Biol 125: 171-182, 2006.

19. Villalobo A, Nogales-González A and Gabius HJ: A guide to signaling pathways connecting protein-glycan interaction with the emerging versatile effector functionality of mammalian lectins. Trends Glycosci Glycotechnol 18: 1-37, 2006.

20. Saussez S, Cucu DR, Decaestecker C, Chevalier D, Kaltner H, André S, Wacreniez A, Toubeau G, Camby I, Gabius HJ and Kiss R: Galectin-7 (p53-induced gene 1): a new prognostic predictor of recurrence and survival in stage IV hypopharyngeal cancer. Ann Surg Oncol 13: 999-1009, 2006.
21. Saussez S, Decaestecker C, Lorfevre F, Cucu DR, Mortuaire G, Chevalier D, Wacreniez A, Kaltner H, André S, Toubeau G, Camby I, Gabius HJ and Kiss R: High level of galectin-1 expression is a negative prognostic predictor of recurrence in laryngeal squamous cell carcinomas. Int J Oncol 30: 1109-1117, 2007

22. Saussez S, Decaestecker C, Lorfevre F, Chevalier D, Mortuaire G, Kaltner H, André S, Toubeau G, Gabius HJ and Leroy $\mathrm{X}$ : Increased expression and altered intracellular distribution of adhesion/growth-regulatory lectins galectins-1 and -7 during tumour progression in hypopharyngeal and laryngeal squamous cell carcinomas. Histopathology 52: 483-493, 2008

23. Saussez S, Decaestecker C, Mahillon V, Cludts S, Cappouillez A, Chevalier D, Kaltner H, André S, Toubeau G, Leroy X and Gabius HJ: Galectin-3 upregulation during tumor progression in head and neck cancer. Laryngoscope (In press).

24. Kopitz J, von Reitzenstein C, André S, Kaltner H, Uhl J, Ehemann V, Cantz $M$ and Gabius HJ: Negative regulation of neuroblastoma cell growth by carbohydrate-dependent surface binding of galectin-1 and functional divergence from galectin-3. J Biol Chem 276: 35917-35923, 2001.

25. Demers M, Magnaldo T and St-Pierre Y: A novel function for galectin-7: promoting tumorigenesis by upregulating MMP-9 gene expression. Cancer Res 65: 5205-5210, 2005.

26. Hyams VJ, Batsakis JG and Michaels L (eds): Tumors of the upper respiratory tract and ear. In: Atlas of Tumor Pathology. Armed Forces Institute of Pathology, Washington D.C, 1998.

27. Wittekind C, Greene FL, Hutter RRP, Kimpfinger M and Sobin LH: TNM Atlas. 5th Edition. UICC Springer, Berlin, 2004.

28. Monhian N, Jewett BS, Baker SR and Varani J: Matrix metalloproteinase expression in normal skin associated with basal cell carcinoma and in distal skin from the same patients. Arch Facial Plast Surg 7: 238-243, 2005.

29. Coussens LM, Tinkle CL, Hanahan D and Werb Z: MMP-9 supplied by bone marrow-derived cells contributes to skin carcinogenesis. Cell 103: 481-490, 2000.

30. Fingleton B: MMPs as therapeutic targets - still a viable option? Semin Cell Dev Biol 19: 61-68, 2008.

31. Scorilas A, Karameris A, Arnogiannaki N, Ardavanis A, Bassilopoulos P, Trangas T, Talieri M: Overexpression of matrix metalloproteinase-9 in human breast cancer: a potential favourable indicator in node-negative patients. Br J Cancer 84: 1488-1496, 2001.

32. Kopitz J, André S, von Reitzenstein C, Versluis K, Kaltner H, Pieters RJ, Wasano K, Kuwabara I, Liu FT, Cantz M, Heck AJR and Gabius HJ: Homodimeric galectin-7 (p53-induced gene 1) is a negative growth regulator for human neuroblastoma cells. Oncogene 22: 6277-6288, 2003.

33. Ahmad N, Gabius HJ, Kaltner H, André S, Kuwabara I, Liu FT, Oscarson S, Norberg T and Brewer CF: Thermodynamic binding studies of cell surface carbohydrate epitopes to galectins- $1,-3$, and -7 : evidence for differential binding specificities. Can J Chem 80: 1096-1104, 2002.

34. André S, Kozár T, Schuberth R, Unverzagt C, Kojima S and Gabius HJ: Substitutions in the N-glycan core as regulators of biorecognition: the case of core-fucose and bisecting GlcNAc moieties. Biochemistry 46: 6984-6995, 2007.

35. André S, Sanchez-Ruderisch H, Nakagawa H, Buchholz M, Kopitz J, Forberich P, Kemmner W, Böck C, Deguchi K, Detjen KM, Wiedenmann B, von Knebel Doeberitz M, Gress TM, Nishimura SI, Rosewicz S and Gabius HJ: Tumor suppressor $\mathrm{p} 16^{\mathrm{INK} 4 \mathrm{a}}$ : modulator of glycomic profile and galectin1 expression to increase susceptibility to carbohydratedependent induction of anoikis in pancreatic carcinoma cells FEBS J 274: 3233-3256, 2007.

36. Gabius HJ (ed): The Sugar Code. Fundamentals of glycosciences. Wiley-VCH, Weinheim, 2008.

37. Nishi N, Shoji H, Seki M, Itoh A, Miyanaka H, Yuube K, Hirashima $M$ and Nakamura T: Galectin-8 modulates neutrophil function via interaction with integrin $\alpha_{\mathrm{M}}$. Glycobiology 13: 755-763, 2003. 